\title{
The Impacts of Trimming Mangroves ${ }^{1}$
}

\author{
Natalia D. Medina-Irizarry and Michael G. Andreu²
}

\section{Introduction}

Mangroves are an important coastal species in Florida and provide people a multitude of benefits that are also known as ecosystem services. These ecosystem services include storm protection, carbon sequestration, erosion prevention, and habitat for endangered wildlife and valuable fishery species (Medina-Irizarry and Andreu 2021). Their many benefits notwithstanding, because mangroves are found in coastal settings, they often block water views. To reduce this obstruction and enhance views, homeowners and businesses sometimes trim mangrove trees. In the context of this publication, trimming includes practices such as limb removal, hedge trimming, pruning, and windowing. Only a few studies have been conducted to quantify the impacts of trimming on mangrove trees in Florida, so our knowledge is limited. This paper will attempt to synthesize our scientific understanding of the impacts of trimming mangrove trees in Florida, as found in the report Mangrove Trimming: A Literature Review of Potential Impacts (Medina-Irizarry and Andreu 2021). This publication is intended for landowners, land managers, and mangrove trimmers who make management decisions concerning mangroves.

Florida is home to three mangrove species: red mangrove (Rhizophora mangle), black mangrove (Avicennia germinans), and white mangrove (Laguncularia racemosa). In general, "mangroves" are trees that are salt tolerant and found in coastal habitats across the tropics and subtropics. The three species found in Florida vary in their tolerance of salt, wave energy, and cold. Black mangroves have the broadest salt tolerance, and white mangroves are the least salt tolerant. Despite the black mangrove's greater salt tolerance, it is the red mangroves that tend to establish at the shoreline, where salinity and wave energy are higher and where inundation periods are longer. Mangrove trees are also limited in where they are found in Florida based on their intolerance of cold/freeze conditions. Of the three, black mangrove is most cold hearty and thus is found furthest north along the Florida coastline. As a result of these varying adaptations, when all three species are present, they tend to be found growing at different areas of exposure to the salt front and intertidal zone (Figure 1).

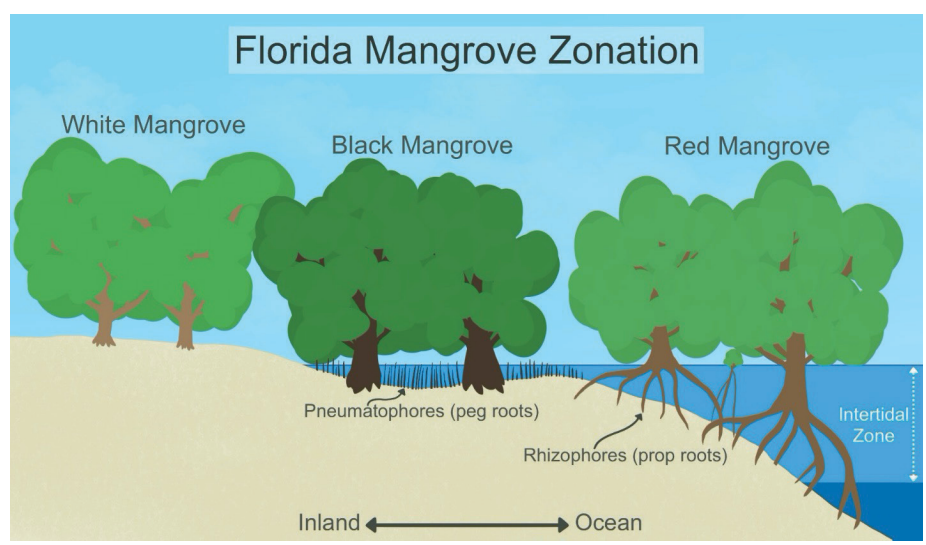

Figure 1. Florida Mangrove Zonation.

Credits: Natalia Medina-Irizarry, UF/IFAS

Trimming mangroves involves the removal of branches, leaves and other parts of the individual tree. In general, heavier trimming (where larger amounts of biomass are removed) reduces the amount of leaf area on a tree, placing greater stress on the individual tree (Figure 2). Collectively,

1. This document is FOR378, one of a series of the School of Forest, Fisheries, and Geomatics Sciences. Original publication date February 2022. Visit the EDIS website at https://edis.ifas.ufl.edu for the currently supported version of this publication.

2. Natalia D. Medina-Irizarry, research assistant for Forest Systems Lab; and Michael G. Andreu associate professor of Forest Systems Lab, School of Forest, Fisheries, and Geomatics Sciences.

The Institute of Food and Agricultural Sciences (IFAS) is an Equal Opportunity Institution authorized to provide research, educational information and other services

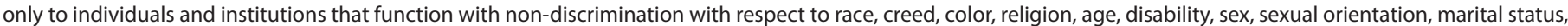

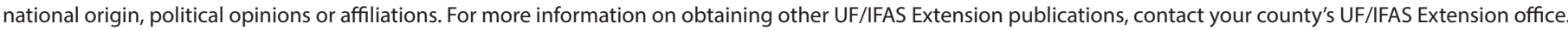
U.S. Department of Agriculture, UF/IFAS Extension Service, University of Florida, IFAS, Florida A \& M University Cooperative Extension Program, and Boards of County Commissioners Cooperating. Andra Johnson, dean for UF/IFAS Extension. 
stressed trees in a stand lead to reduced resilience and ability to provide desired ecosystem services. In this context, resilience is the plant's ability to resist damage or recover quickly following a disturbance.

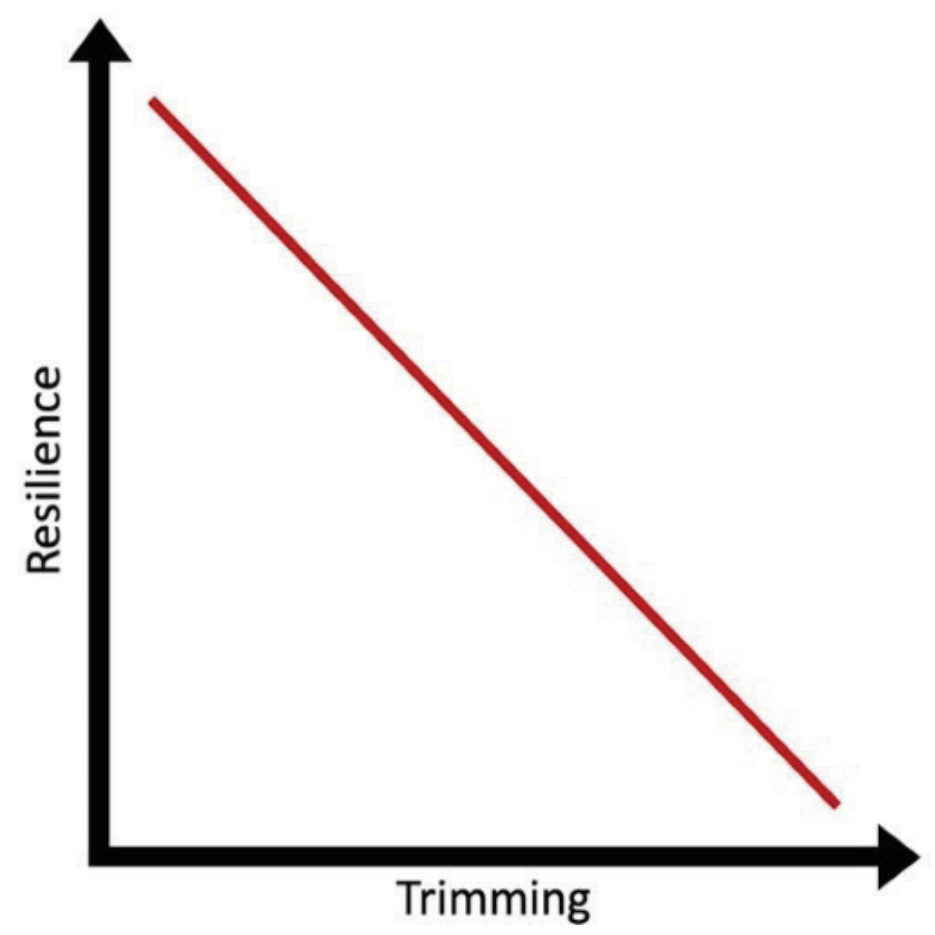

Figure 2. This conceptual graph depicts the relationship between resilience and trimming. As trimming increases, resilience decreases. Credits: Natalia Medina-Irizarry, UF/IFAS

To ensure that ecosystem services persist and to provide guidance to homeowners, a law has been enacted that regulates the management of mangrove trees and mangrove forests. Mangroves are protected under the 1996 Mangrove Trimming and Preservation Act (MTPA), which, with some exceptions, regulates the alteration of mangroves statewide. The MTPA primarily uses mangrove tree heights to define when homeowners may trim their mangroves, when professional mangrove trimmers are required, and when authorization by the Florida Department of Environmental Protection (FDEP) is required (Figure 3). For additional information about the 1996 Mangrove Trimming and Preservation Act, see the following resources: Trimming Mangroves and 1996 MTPA. This publication focuses on the impacts mangrove trees and mangrove stands experience from various trimming techniques according to the MTPA. However, due to the lack of studies that adhere to MTPA guidelines, this publication includes data from studies that pre-date the MTPA. Therefore, not all trimming methods examined fall within MTPA guidelines.

\section{Allowable Trimming}

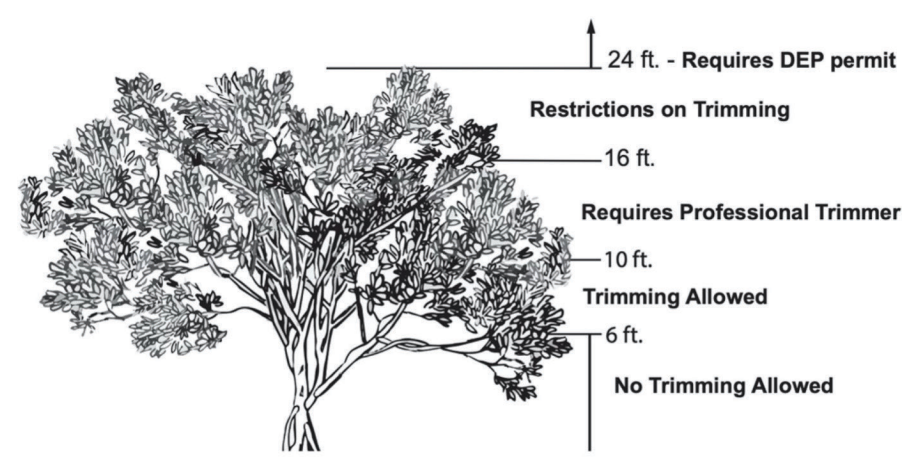

Figure 3. Allowable trimming per the 1996 Mangrove Trimming and Preservation Act.

Credits: Trimming Mangroves, FDEP

\section{What are the impacts of trimming mangroves? \\ Direct Impacts of Trimming}

The impacts observed on individual trees following a trimming event are what we consider direct impacts; these impacts differ among the three species found in Florida. Field observations indicate that red mangroves are more sensitive to trimming and are the slowest to recover from a trimming event. When a mixed stand of red, black, and white mangroves was trimmed, the white mangroves recovered (achieved canopy closure) 3-5 times faster than red mangroves (Snedaker et al. 1992). The red mangrove's inefficient recovery can be attributed to its inability to grow new branches from older parts of the tree (Gill and Tomlinson 1971; Snedaker et al. 1992). To avoid this, red mangrove branches should not be trimmed back further than where they measure $2.5 \mathrm{~cm}$ in diameter (Gill and Tomlinson 1971). In this scenario, the black and white mangroves demon-strated their ability to produced new leaves and shoots via their secondary meristems (Snedaker et al. 1992).

The seasonality of trimming events is also an essential factor in the recovery of mangroves. Trimming treatments on predominantly red mangrove stands that occur in the winter (December) produce significantly fewer leaves and flowers the following year (Ellis and Bell 2004). Such interruptions disrupt the life cycle of mangrove trees, which results in further indirect impacts. A direct comparison between pruning events that occurred in spring (April) and fall (October) showed mangroves pruned during the spring recovered far quicker (Carlton 1974). Quicker recoveries and less significant impacts on productivity have also been observed among mangrove roots cut during the summer (August) compared to cuts initiated in the winter (December) (Gill and Tomlinson 1977). The seasonal 
response to trimming has not been measured for black and white mangroves.

\section{Indirect Impacts of Trimming}

Indirect impacts can include shifts in ecosystem services, ecosystem function, or stand structure. For instance, an ecosystem service affected by trimming mangroves is storm protection. Reduced average tree heights following trimming treatments affect the ability of the trees to buffer winds and wave action during storm events. Likewise, if trimming treatments heavily thin the mangrove canopy density, this, too, will reduce the ability of the trees to attenuate wind and wave action (Othman 1994). In addition, thinner mangrove stands are also less likely to minimize erosion associated with storm surge and high-energy wave activity. Moreover, studies by Lippi and Osborne showed that trimmed black mangrove trees experienced increased stress during storm events compared to untrimmed black mangroves. Because trimmed black mangroves experience more stress during extreme weather events, we can expect the impact to reduce the resilience and growth rates of the mangroves. Based on what we know, it might be reasonable to expect a similar stress response from trimmed red and white mangroves.

Gaps (openings) in the canopy created by trimming mangroves increase the opportunity of non-native species with fast germination, high reproduction rates, and good salt tolerance to invade. In Florida, Brazilian peppertree (Schinus terebinthifolius) is an invasive species with such characteristics and often invades disturbed coastal forests. Brazilian peppertree is also known to have allelopathic characteristics. Allelopathy is an organism's ability to produce biochemicals that inhibit the growth, survival, and reproduction of other plants, such as mangroves. When mangrove forests consisting of mostly red and black mangroves were exposed to high levels of Brazilian peppertree fruits, the mangroves experienced reduced growth rates due to allelopathy (Donnelly et al. 2008). Observations have been recorded of Brazilian peppertree and other invasive species invading trimmed mangrove stands by taking advantage of the canopy gaps formed (Parkinson et al. 1999). Invasive species displace native plants which results in altered stand structure, hydrology, and nutrient pools, and, consequently, modified ecosystem services and function.

\section{Climate Change and Trimming}

As sea level rises, mangroves may be exposed to higher levels of salinity and longer periods of inundation. This places mangroves in a state where they are less resilient against the invasion of non-native species, cold stress, and mechanical alteration. Additionally, climate change is expected to increase Florida's frequency and intensity of storms, and, therefore, trimmed mangroves will become increasingly vulnerable. Vulnerable mangroves are more prone to mortality, meaning the coasts facing an increased occurrence of storms, strong winds, water surges, and sea-level rise will experience higher rates of erosion. Mangroves also have an influential role in blue carbon storage (blue carbon is the carbon stored by marine and coastal ecosystems). However, as live mangrove biomass decreases, whether by trimming or reduced growth rates from stress, the amount of carbon stored also decreases. Knowing carbon dioxide $\left(\mathrm{CO}^{2}\right)$ is a driving force of climate change, management goals must be improved to maximize carbon sequestration. Moreover, if mangrove forest health continues to decline, other ecosystem services (such as wildlife habitat and fisheries spawning sites) will also be harmed.

\section{How can homeowners and land managers reduce these impacts?}

The following list is applicable to all mangrove species found in Florida unless stated otherwise.

1. Mechanical alteration should be limited in the amount of biomass removed and number of trimming events. At the least, biomass removal should not exceed the amounts indicated in the MTPA.

2. The compounded impacts of multiple trimming events are not fully understood, but in general, more trimming leads to increased stress. Keep trimming events to a minimum within a stand.

3. Trimming during the spring or summer months causes less stress on mangrove trees compared to trimming during the fall or winter months. Timing the trimming event to occur before the tree's maximum leaf production (spring) will maximize the ecosystem services provided within a trimmed ecosystem.

4. Adhere to regulatory restrictions. Mangrove trimming professionals should be contacted when needed, and the tools used should be sharp and clean.

5. Regarding red mangroves, trimming cuts should not occur where the branch exceeds $2.5 \mathrm{~cm}$ in diameter. Such practices lead to the loss of meristems, reducing productivity and stopping growth altogether. 


\section{Reference List}

Carlton, J. M. 1974. "Land-Building and Stabilization by Mangroves." Environmental Conservation 1 (4): 285-294. https://doi.org/10.1017/S0376892900004926

Donnelly, M. J., D. M. Green, and L. J. Walters. 2008. "Allelopathic Effects of Fruits of the Brazilian pepper Schinus terebinthifolius on Growth, Leaf Production and Biomass of Seedlings of the Red Mangrove Rhizophora mangle and the Black Mangrove Avicennia germinans." Journal of Experimental Marine Biology and Ecology 357 (2): 149-156. https://doi.org/10.1016/j.jembe.2008.01.009

Ellis, W. L., and S. S. Bell. 2004. "Canopy Gaps Formed by Mangrove Trimming: An Experimental Test of Impact on Litter Fall and Standing Litter Stock in Southwest Florida (USA)." Journal of Experimental Marine Biology and Ecology 311 (2): 201-222. https://doi.org/10.1016/j. jembe.2004.05.008

Gill, A. M., and P. B. Tomlinson. 1971. "Studies on the Growth of Red Mangrove (Rhizophora mangle L.) 3. Phenology of the Shoot." Biotropica 3 (2): 109-124. https:// doi.org/10.2307/2989815

Gill, A. M., and P. B. Tomlinson. 1977. "Studies on the Growth of Red Mangrove (Rhizophora mangle L.) 4. The Adult Root System." Biotropica 9 (3): 145-155. https://doi. org/10.2307/2387877

Lippi, D., and T. Osborne. "The Consequences of Regulated Trimming and Hurricane Stressors on Secondary Growth, Wound Wood Production, and Chlorophyll Content of Black mangroves (Avicennia germinans)." UF IFAS, 1-20. https://soils.ifas.ufl.edu/media/soilsifasufledu/sws-mainsite/pdf/technical-papers/Lippi_Daniel_Six_Month_Embargo.pdf

Medina-Irizarry, N., M. and Andreu. 2021. "Mangrove Trimming: A Literature Review of Potential Impacts." Florida Department of Environmental Protection, Tallahassee FL, 1-33.

Othman, M. A. 1994. "Value of Mangroves in Coastal Protection.” Hydrobiologia 285:277-282. https://doi. org/10.1007/BF00005674

Parkinson, R. W., M. Perez-Bedmar, and J. A. Santangelo. 1999. "Red Mangrove (Rhizophora mangle L.) Litter Fall Response to Selective Pruning (Indian River Lagoon, Florida, USA)." In Diversity and Function in Mangrove Ecosystems, edited by Dodd R. S. Developments in
Hydrobiology, vol 145. Springer, Dordrecht. pp. 63-76. https://doi.org/10.1007/978-94-011-4078-2_7

Snedaker, S. C., M. S. Brown, E. J. Lahmann, and R. J. Araujo. 1992. "Recovery of a Mixed-Species Mangrove Forest in South Florida following Canopy Removal." Journal of Coastal Research 9 (4): 919-925. https://www.jstor.org/ stable/4298045 